\title{
Debates e disputas sobre a legalização do aborto no Brasil:
} A laicidade na corda bamba ${ }^{1}$

\author{
Debates and disputes about the legalization of abortion in Brazil: laicity on the tightrope \\ Emilly Joyce Oliveira Lopes Silva ${ }^{2}$ \\ Luciana Patrícia Zucco ${ }^{3}$
}

Resumo: Este artigo tem como objetivo principal analisar a discussão sobre a legalização do aborto no Brasil a partir dos dados coletados na audiência pública do Supremo Tribunal Federal acerca da Arguição de Descumprimento de Preceito Fundamental n. 442 (ADPF 442), tendo como referência conceitual a categoria laicidade. Para tanto, partimos de um apanhado histórico sobre a legalização do aborto e as definições de laicidade. $\mathrm{Na}$ sequência, analisamos os principais argumentos apresentados na audiência pública, ocorrida em 2018, segundo a técnica da análise de conteúdo, na modalidade temática. Por fim, discutimos as possibilidades da categoria laicidade para o debate em torno da descriminalização do aborto, sendo que esta leitura se apresenta como um dos principais resultados.

Palavras-chave: Laicidade, aborto, STF

\begin{abstract}
This article has as main objective to analyze the legalization of abortion in Brazil from the "laicity" category, with data collected in the public hearing of the Federal Supreme Court about ADPF442. To do so, we start with a brief discussion about the legalization of abortion and the definitions of laicity. Following, the main arguments presented at the public hearing are analyzed. Finally, we discuss the possibilities of the "laicity" category for the debate on the decriminalization of abortion.
\end{abstract}

Keywords: Laicity, abortion, ST

\footnotetext{
${ }^{1}$ O presente trabalho foi realizado com apoio da Coordenação de Aperfeiçoamento de Pessoal de Nível Superior - Brasil (CAPES) - Código de Financiamento 001.

${ }^{2}$ Emilly Joyce Oliveira Lopes Silva é doutoranda - Interdisciplinar em Ciências Humanas/ UFSC>

${ }^{3}$ Luciana Zucco é graduada em Serviço Social pela Universidade Federal de Santa Catarina, possui mestrado em Serviço Social pela Pontifícia Universidade Católica do Rio de Janeiro (1997) e doutorado em Ciências da Saúde pelo Programa de Pós-Graduação em Saúde da Criança e da Mulher do Instituto Fernandes Figueira/ Fundação Oswaldo Cruz (2007). Atualmente, é professora Adjunta Nível III do Departamento de Serviço Social do Centro Socioeconômico da Universidade Federal de Santa Catarina; coordena o Núcleo de Estudos e Pesquisas em Serviço Social e Relações de Gênero (NUSSERGE-UFSC); é pesquisadora e integrante do Instituto de Estudos de Gênero da UFSC (IEG-UFSC).
} 


\section{Introdução}

O presente artigo tem por objetivo analisar as discussões sobre a legalização do aborto no Brasil a partir da categoria “laicidade”. Neste recorte, optamos como cenário de coleta de dados a audiência pública sobre a descriminalização do aborto até a $12^{\mathrm{a}}$ semana de gestação, que ocorreu no Supremo Tribunal Federal (STF), nos dias 3 e 6 de agosto de 2018. A audiência, proposta pela ministra Rosa Weber, contou com 49 expositores/as escolhidos/as de forma democrática, a fim de representar os mais diferentes posicionamentos da sociedade em relação ao tema. A partir desses diferentes pontos de vista sobre a despenalização da Interrupção Voluntária da Gravidez (IVG), defendemos como premissa a complexa relação entre laicidade e a discussão sobre o aborto. Para abordarmos essa relação, nos amparamos nas discussões teóricas que debatem a laicidade e suas múltiplas possibilidades analíticas para o tema da Arguição de Descumprimento de Preceito Fundamental n. 442 (ADPF442 ${ }^{1}$.

De acordo como Micheline Milot (2008), a separação entre Estado e Igreja, designada pela laicidade, implica em dois componentes principais: de um lado, a independência do Estado em relação às igrejas; do outro, a liberdade das religiões perante o Estado. Assim, o Estado laico precisa lidar com os diferentes modos de se viver em uma sociedade, ao mesmo tempo em que deve garantir a integração política e jurídica de grupos minoritários, sejam eles de base religiosa, racial, étnica, sexual ou outras. Partindo dessas proposições, explicitaremos as continuidades e descontinuidades argumentativas em relação à legalização do aborto, em particular, os tensionamentos entre os diferentes grupos e suas posições sobre a IVG.

Não somente no Brasil, mas em vários outros países do mundo o debate sobre a legalização foi e é atravessado por marcos religiosos, sobretudo cristãos (VAGGIONE, 2006; RUIBAL, 2014). Segundo Alba Ruibal (2014), na América Latina, o principal entrave para o avanço dos direitos sexuais e reprodutivos é a forte mobilização dos fundamentalismos religiosos. O ideal de “família”, dentro dos parâmetros conservadores, é central para esses fundamentalistas, que defendem a manutenção dos papéis tradicionais de gênero. Assim, o aborto segue ponto de tensionamento entre os avanços dos movimentos feministas e o forte poder de influência da Igreja Católica e das igrejas evangélicas nos países latinos. Esse conflito pode ser facilmente percebido no debate sobre ADPF 442, ainda que não haja, como se pode imaginar num primeiro momento, grupos opostos tão evidenciados. 
Um recuo na história nos permite compreender de forma mais ampla essa mobilização por parte dos fundamentalistas religiosos. Incialmente, é necessário ter em mente que o cristianismo nem sempre condenou, de maneira explícita, a interrupção da gravidez realizada pelas mulheres. De acordo com Jane Hurst (2000), “A opinião dos eruditos da Igreja em relação ao aborto nunca foi unânime” (p. 9). Desde 1869, com a declaração do Papa Pio IX defendendo a excomunhão de quem pratica o aborto, o entendimento geral da Igreja católica é contrário à IVG. Contudo, segundo Hurst, as opiniões dos teólogos nem sempre estiveram de acordo com essa definição.

A autora faz uma distinção entre duas funções da igreja. A primeira diz respeito ao papel legislativo, personificado no Código de Direito Canônico, que define regras e punições para todas as pessoas católicas. A segunda função é a de educadora, conhecida também como magistério. O magistério é responsável pelas questões de fé e de moral. Nesses quesitos, o papa é considerado “capaz de ensinar de modo infalível” (HURST, 2000, p. 10). É curioso observar que a questão do aborto não faz, nem nunca fez parte do magistério e, por isso, não é regida pela infalibilidade papal. Isso significa, para Hurst (2000), que o debate em relação ao tema é muito mais “aberto” do que geralmente se imagina.

Outro ponto de destaque a ser analisado em relação à discussão teológica sobre o aborto é a defesa da vida, que aparece como um dos mais importantes argumentos para que a prática seja criminalizada. Segundo o trabalho de Jane Hurst (2000), é somente a partir de meados do século XX que a Igreja católica desenvolverá “o conceito teológico de proteção da vida desde o momento da contracepção” (p. 36). A autora afirma que não está explícita a motivação para este posicionamento moderno da Igreja; o mais frequente é que a defesa do direito à vida seja uma reação ao que se entende como “ameaça à família”.

Ao mesmo tempo em que se observa uma mudança no entendimento da Igreja sobre o tema, a sociedade também viveu transformações significativas que interferiram diretamente nas visões sobre o aborto. Para Thomas Laqueur (2001), é no século XVII que se constrói a diferenciação biológica entre homens e mulheres. Antes disso, prevalecia o modelo do sexo único, que pressupunha a inversão do órgão reprodutor masculino nas mulheres. A criação do modelo dos dois sexos é mais política que científica, porque, a partir desse momento, o sexo passa a ser entendido como uma categoria ontológica, ou seja, como algo fundante para os modos de ser/existir (LAQUEUR, 2001). 
Ademais, se incorporarmos a concepção de biopolítica, conforme as proposições de Foucault (2004), será possível perceber que o controle sobre os corpos se encontra na base do que entendemos por modernidade. Foucault (2004) discorre sobre a transformação histórica na forma comos os seres humanos lidam com a vida e com a morte. Essa transformação passa pelo domínio biológico dos corpos num momento em que a vida ganha centralidade na história humana. Nesse contexto, “os mecanismos de poder se dirigem ao corpo, à vida, ao que faz proliferar, ao que reforça a espécie, seu vigor, sua capacidade de dominar ou sua aptidão para ser utilizado” (FOUCAULT, 2004, p. 138). Assim, a virada moderna tem na sexualidade um valor essencial, ao mesmo tempo em que funda um modelo de diferenciação entre homens e mulheres que define toda a organização da sociedade.

Essa diferenciação pode ser vista como o cerne das sociedades modernas. Ao tratar do contrato sexual, Carole Pateman (1993) demonstra como as teorias tradicionais do contrato social ignoram metade da história, uma vez que a dominação das mulheres pelos homens está na origem do contrato. De acordo com a autora: “A metade perdida da história conta como uma forma caracteristicamente moderna de patriarcado se estabelece” (PATEMAN, 1993, p. 16). Para ela, o contrato social trata da liberdade, enquanto o contrato sexual fala da sujeição.

Nesse sentido, a conformação de indivíduo livre detentor de direitos não é universal, pois se limita aos homens. Na sociedade moderna, a diferença sexual exclui metade da população dessa concepção de indivíduo. Para Naiara Pinheiro dos Santos (2015), com o surgimento dos Estados modernos surge também um ideal de sujeito: “ocidental, homem, branco, adulto, heterossexual, preferencialmente católico, e/ou agnóstico, a depender do contexto” (p. 149). Assim, a normatização de um modelo marginaliza parte significativa da população do acesso a direitos básicos, como a liberdade de consciência, trabalho, educação, justiça e, de modo geral, a uma existência digna (SANTOS, 2015).

Do ponto de vista dos direitos humanos, as questões de gênero são muito centrais para a compreensão das sociedades democráticas, dos direitos das mulheres (e demais minorias) e da própria laicidade como um princício. Ao remontar a história da invenção dos direitos humanos, Lynn Hunt (2009) mostra como mulheres, minorias religiosas, escravos/as, negros/as livres, pessoas sem propriedade, além de estrangeiros, insanos, prisioneiros e crianças foram excluídos/as de uma noção universal dos direitos no final do século XVIII. No entendimento da autora, essa observação trazida para a atualidade pode revelar o fracasso dos direitos humanos 
referenciados por uma concepção universal, o que não significa, contudo, que devamos abrir mão dessa concepção. Ela destaca também que a universalidade dos direitos não os exime de conflitos, nem os torna absolutos.

Com relação à interrupção da gestação, segundo Giulia Galeotti (2007), até o século XVIII, o aborto tende a ser tratado como uma questão íntima das mulheres, muitas vezes prevalecendo, ao menos no senso comum, a compreensão de que o feto é uma extensão do corpo da mulher. Ainda que essa perspectiva não seja monolítica, sua ruptura definitiva só acontecerá na modernidade, com a ascensão do pensamento Iluminista. O desenvolvimento das ciências permitiu que o feto fosse melhor visualizado em sua individualidade. Assim, os Estados modernos se vêem no conflito entre a defesa de duas entidades de direito: o feto e a mãe, optando pela tutela do primeiro. Na leitura de Galeotti, essa visão prevaleceu por muito tempo, até que na segunda metade do século XX os direitos das mulheres se tornam um vetor relavante nesse processo e diversos Estados decidem descriminalizar a IVG.

Os movimentos feministas têm papel central na descriminalização do aborto. Para Lucila Scavone (2001), é com a publicação do Segundo Sexo, de Simone de Beauvoir, em 1949, que se observa uma transformação significativa nessa questão. Segundo a autora, ao questionar a função da maternidade, opondo-se às forças conservadoras do pós-guerra, que se ancoravam na família, na moral e nos bons costumes, o livro de Beauvoir tornou-se um ponto de clivagem na história do feminismo, caracterizada pela passagem do "feminismo igualitarista" para o feminismo centrado na "mulher-sujeito". Assim, os direitos sexuais e reprodutivos se tornam peça-chave, sobretudo nos anos 60 e 70, nas lutas pela emancipação das mulheres. De acordo com Galeotti (2007, p. 131):

Neste quadro, a legislação que criminaliza a interrupção voluntária da gravidez torna-se símbolo da expropriação do corpo e da identidade feminina. É nesta fase que ganha forma a ideia do aborto como direito civil, o primeiro de tantos a reclamar. Prática extremamente dolorosa e perigosa para a mulher, duramente hostilizada pelos movimentos do século XIX que viam nele mais um instumento da sexualidade masculina prevaricadora, o aborto transforma-se na reivindicação unificadora do feminismo, capaz, mais do que qualquer outra, de unir mulheres de diferentes classes, culturas e idades.

É necessário ressaltar que, mesmo em torno do aborto, não há unicidade entre os diversos feminismos que derivam da vaga noção de igualdade entre homens e mulheres. Ainda assim, é 
inegável que a luta pela legalização do aborto foi central nos países da Europa e nos Estados Unidos e segue tendo grande importância onde a despenalização efetiva ainda não foi alcançada, como é o caso do Brasil. A discussão promovida por grupos feministas tem alcance cada vez maior na esfera pública. Com isso, a resposta da Igreja - entendendo aqui que a luta pela legalização do aborto integra a noção de ameaça à família - também se intensifica, estabelecendo uma tensão que, conforme a premissa desse artigo, pode ser melhor compreendida pela categoria laicidade.

Na atualidade, a laicidade desponta como um tema central para garantir os valores da igualdade e da liberdade. De acordo com a socióloga Micheline Milot (2008, p. 45):

La cuestión de la laicidad nos lleva a considerar uno de los grandes desafíos que todas las sociedades plurales deben enfrentar, tanto desde un punto de vista político como jurídico y social: se trata de encontrar como vivir juntos pacíficamente, en un momento histórico en que la diversidad de concepciones de vida (morales, religiosos y filosóficos) nunca han sido tan marcada.

A partir desta constatação, Milot (2008) identifica dois problemas capitais. O primeiro é caracterizado pelos diferentes modos de se viver em uma sociedade, conforme fica explícito no trecho anterior. O segundo, relacionado diretamente ao primeiro, diz respeito às "modalidades políticas y jurídicas de integración de las minorías (sexuales, religiosas, autóctonas u otras)” (MILOT, 2008, p. 45). Este último aspecto é caro ao tema proposto aqui, uma vez que as mulheres, principais beneficiárias da legalização do aborto, conformam uma minoria de direitos.

É preciso ter em mente que a organização social sustentada pela diferenciação de gênero relega às mulheres o papel do cuidado. O tempo que homens e mulhers disponibilizam para funções relacionadas à criação dos filhos e trabalhos domésticos é completamente diferente (DELPHY, 2015; BESSIN, 2016). Desse modo, a gestação não apenas ocorre no corpo da mulher, como também lhe atribui uma série de obrigações relacionadas ao cuidado da criança, que podem resultar em um abandono de seus projetos de vida ou sobrecarga de atribuições. Cabe lembrar ainda que o Estado não é, de forma hegemônica, um espaço em que os direitos das mulheres são discutidos a partir do interesse das próprias mulheres, o que estabelece uma rede complexa de relações entre direitos das mulheres, direitos sexuais e reprodutivos, papéis de gênero e democracia. Neste trabalho, interessa-nos, sobretudo, como a laicidade atravessa essa ampla rede de relações. 
A laicidade é definida como separação entre religião e realidades profanas. No entanto, segundo Milot (2008), essa definição permanece mais como um ideal, sendo difícil observar uma separação tão precisa entre Estado e religião. Nos estados ditos pré-modernos, a organização política era, de certo modo, garantida pela fé ou pela associação com alguma instituição religiosa - basta lembrar que os governos monárquicos, muitas vezes, sustentavam-se pelo caráter “divino” do rei, cujo poder emanava da vontade direta de Deus. O Estado moderno, em contrapartida, rompe com essa junção, tornando a religião uma questão privada (TAYLOR, 2010).

O Estado moderno é um Estado democrático. Por isso, a relação entre laicidade e democracia é fundamental. Para que o Estado possa representar todos os/as cidadãos/ãs de forma equânime é necessário que se coloque em uma posição distanciada das religiões, para garantir a liberdade de culto às mais diversas formas de doutrina. Segundo Roberto Blancarte (2008), a laicidade é, portanto, um regime de convivência social cujas instituições políticas estão legitimadas, principalmente, pela soberania popular e não mais por elementos religiosos. De acordo com o pesquisador, cabe acentuar a laicidade como um processo e não como algo estanque, definido, não-mutável, sendo impossível afirmar que determinado Estado seja plenamente laico. Trata-se, desse modo, de um terreno em constante disputa, atravessado por diferentes interesses.

Para explicar o que é laicidade, Carmen Villarino-Bracho (2005) recorre à definição feita pelo jurista Henry Capitant, em 1936: "la laicidad es una concepción política que implica la sociedad civil y la sociedad religiosa, no ejerciendo el Estado ningún poder religioso y las Iglesias ningún poder civil" (apud BRACHO, 2005, p. 145). Com base nessa conceituação, ela observa três pontos que são de fundamental importância para a compreensão do que é laicidade: 1) concepção político-constitucional, que se alinha a um sistema político baseado na Constituição dos Estados Unidos ou na Revolução Francesa; 2) caráter relacional do conceito, uma vez que sua caracterização não se dá pela ausência de uma relação; 3) distinção entre duas formas de poder, o político e o religioso. Dessa forma, a laicidade se aproxima de um ideal político, de origem moderna, que pressupõe a separação de esferas de poder: não cabe ao Estado exercer qualquer poder religioso, nem às igrejas o exercício do poder civil.e (2012), a laicidade sustentase em 3 pilares: 1) respeito à liberdade de consciência; 2) autonomia do político em relação ao religioso; 3) garantia à igualdade e a não discriminação. Nessa perspectiva, a liberdade religiosa 
integra o Estado laico, mas não é sua única característica. A liberdade de consciência ou liberdade religiosa corresponde, como se pode imaginar, à garantia de que todas as pessoas sejam livres para manifestar suas crenças ou mesmo a ausência delas. Essa liberdade tem profunda relação com o processo de secularização, pois os Estados que se organizavam por meio de uma religião não permitiam que os cidadãos mantivessem suas crenças de forma livre e opcional.

Charles Taylor (2010) observa que, historicamente, ocorreu uma mudança significativa nas “condições da fé”. Para ele, é evidente que a "passagem de uma sociedade em que a fé em Deus é inquestionável e, de fato, não problemática, para uma na qual a fé entendida como uma opção entre outras e, em geral, não a mais fácil de ser abraçada” (TAYLOR, 2010, p. 15). Dessa forma, em um Estado democrático de direito é fundamental que as estruturas jurídicas e políticas assegurem que todos/as cidadãos/ãs possam escolher suas crenças e como manifestá-las.

Assim, se entendemos o Estado laico como um equilíbrio entre liberdade de consciência, não religiosidade do Estado e garantia à igualdade, a prevalência de qualquer um desses aspectos em detrimento de outro pode ferir o princípio da laicidade. Ao observamos o processo brasileiro, podemos perceber que o respeito à liberdade de consciência existe, mas quase sempre limitado àqueles que manifestam a fé cristã, de modo semelhante ao que acontece com a garantia à igualdade e a não discriminação. A autonomia do político frente ao religioso é garantida pela Constituição, mas esbarra em uma forte tradição católica e na estratégia, sobretudo dos neopentecostais, de ocupar os cargos políticos. Dessa maneira, muitas das decisões políticas são pautadas por valores religiosos que não correspondem aos princípios da liberdade e da igualdade.

Esse equilíbrio é essencial para a análise do debate sobre a legalização do aborto, pois, do ponto de vista da laicidade, as pessoas que seguem o cristianismo podem manifestar suas opiniões e apresentar argumentos pautados pela moral cristã; ao mesmo tempo, o Estado precisa garantir a igualdade entre aqueles/as que creem e os/as que não creem, mantendo-se distante em matéria religiosa. O conflito entre tais aspectos se faz visível nas discussões sobre os direitos sexuais e reprodutivos, uma vez que a prevalência de uma moral religiosa em decisões do Estado se consolida drasticamente no Brasil. No caso da audiência pública sobre a ADPF442, esse aspecto se faz presente na composição dos/as expositores/as. No segundo dia da audiência foram ouvidas as principais religiões e igrejas em atuação no Brasil, por meio de instituições diversas - apesar da ausência de duas representações que poderiam ter complexificado o debate: a das religiões de matriz africana e a dos budistas. 
Na sequência, apresentamos o caminho percorrido para a construção dos dados e discussão dos resultados.

\section{Metodologia}

No dia 3 de agosto do ano de 2018, às 08:28 (horário de Brasília), a presidente do Supremo Tribunal Federal do Brasil, Ministra Carmén Lúcia, deu início à audiência pública para debater a ADPF442. No decorrer dos dois dias de apresentações, representantes de instituições diversas e da sociedade civil puderam apresentar argumentos relacionados ao tema da ADPF 442, ou seja, ao descumprimento de preceito fundamental em 2 dos artigos que criminalizam o aborto no Brasil. Nosso foco, para esta análise, foi o viés religioso que perpassa a discussão sobre a possibilidade de legalização do aborto, com atenção especial para a laicidade como um valor democrático e de direitos humanos.

Do ponto de vista metodológico, o trabalho se ampara em uma discussão conceitual e cotextual sobre a laicidade, as sociedades modernas e as discussões de gênero para compreender de maneira mais profunda a discussão sobre a legalização do aborto. Nesse sentido, é possível afirmar que o artigo conjuga um panorama histórico, em uma perspectiva interdisciplinar, para a compreensão de um problema atravessado por múltiplos fatores. Ainda que a coleta de dados se dê em um momento muito recente, nossa perspectiva de análise considera fundamental estabelecer conexões entre este presente complexo e suas referências conceituais. Dito de outro modo, não é possível debater as leis sobre o aborto no Brasil hoje sem uma compreensão verticalizada da construção dos direitos humanas, dos pilares da sociedade moderna, das múltiplas pautas feministas e das transformações históricas no entendimento religioso sobre a questão.

Com vistas a assegurar a visibilidade do processo de construção dos dados, é importante esclarecermos que a coleta compreendeu dois momentos, com a categorização de temas e seus sentidos referentes ao aborto, tendo como técnica de análise a modalidade temática sugerida por Bardin (2007). Em um primeiro momento, analisamos a lista divulgada pelo STF (BRASIL, 2018), observando quem são os/as expositores/as. Conforme o documento, subdividimos os/as participantes em quatro eixos argumentativos: saberes técnico-científicos (STC); saberes pessoais-opinativos (SPO); saberes religiosos-teológicos (SRT) e saberes ético-filosóficos (SEF). É importante destacar que esses eixos não são homogêneos ou estanques, havendo, 
portanto, múltiplas possibilidades de entrecruzamento entre eles. Por isso, defendemos que a observação desses grupos e seus posicionamentos nos possibilitou um panorama geral sobre os argumentos que eles utilizam em relação à legalização do aborto.

O segundo procedimento foi a observação da audiência pública, por meio da transmissão exibida ao vivo, pela televisão, no canal da TV Justiça. Além de acompanhar as discussões e falas de todos/as expositores/as, também foi importante a constituição de um diário de campo, com anotações sobre as impressões geradas pelas 49 exposições, principais argumentos apresentados e algumas análises prévias. Nesse sentido, foi fundamental acompanhar os argumentos dos/as expositores/as, estabelecendo relações com os valores religiosos, bem como com os estudos de diferentes áreas do conhecimento, sobretudo, no que diz respeito aos estudos feministas e aos direitos sexuais e reprodutivos.

A partir do quadro geral com a lista de expositores/as e das anotações do diário de campo, o próximo passo foi uma análise dos argumentos apresentados, na tentativa de estabelecer alguns eixos principais que foram mais frequentemente mobilizados. A fim de compreendermos melhor a composição desse debate, separamos as diferentes exposições em quatro eixos temáticos, que não são estanques, nem limitam a diversidade dos argumentos apresentados. Como ferramenta metodológica, eles apenas nos auxiliam no entendimento das principais tendências argumentativas que permearam o debate na audiência pública.

A ideia central era encontrar ponto de intersecção entre a discussão feita nos dois dias de audiência pública e a categoria laicidade, observando tanto a fala dos grupos religiosos quanto dos pretensamente seculares. Por isso, optamos por aprofundar a escala de análise, observando de modo mais pormenorizado algumas exposições que dialogam diretamente com as definições de Estado laico.

A coleta foi realizada nos meses de junho a agosto de 2018, e a discussão dos resultados projetou os temas e sentidos organizados por eixos: aborto e saberes; aborto e religião; aborto e lacidade. Tal organização deu visibilidade à relação estabelecida entre narrativas individuais/grupos e culturais ou, ainda, à dinâmica entre as dimensões subjetivas/coletivas e objetivas. Cabe ressaltar que as reconstruções dos acontecimentos ocorridos e suas interpretações, em certa medida, foram reescritos, pois como afirma Clifford (1990, p. 54) “escrever é sempre, em algum grau, reescrever”. Em resumo, a coleta e análise se pautou pela 
organização temática do que foi apresentado na audiência pública e pela análise dos dados à luz das discussões teóricas e históricas apresentadas inicialmente.

\section{DISCUSSÃO DOS RESULTADOS}

O quadro abaixo resume, de modo mais geral, os principais eixos temáticos que foram definidos a partir de nossa análise:

Tabela 1. Eixos argumentativos (EA)

\begin{tabular}{|c|c|}
\hline Saberes técnico-científicos (STC) & $\begin{array}{l}\text { Campo da saúde, práticas médicas e saúde pública } \\
\text { Temas Socioeconômicos, históricos, antropológicos e demográficos } \\
\text { Temas Jurídicos } \\
\text { Dados numéricos e pesquisas } \\
\text { Estudos feministas e de gênero }\end{array}$ \\
\hline Saberes pessoais-opinativos (SPO) & $\begin{array}{l}\text { Experiências pessoais ou de um grupo específico } \\
\text { Opiniões individuais ou de um grupo específico } \\
\text { "Lugar-de-fala” }\end{array}$ \\
\hline Saberes religiosos-teológicos (SRT) & $\begin{array}{l}\text { Dogmas religiosos } \\
\text { Fundamentos bíblicos } \\
\text { Crenças pessoais ou coletivas } \\
\text { Livros sagrados }\end{array}$ \\
\hline Saberes ético-filosóficos (SEF) & $\begin{array}{l}\text { Questões éticas e/ou morais } \\
\text { Valoração da vida } \\
\text { Certo e errado }\end{array}$ \\
\hline
\end{tabular}

Fonte: Autoras.

Conforme os argumentos apresentados por cada uma das pessoas que discursou na audiência pública sobre a ADPF, estabelecemos alguns temas mais recorrentes (à direita) e os saberes que foram mobilizados. É interessante destacar, no entanto que em nossa análise observamos uma prevalência da tendência técnico-científica nas falas dos/as expositores/as. Essa prevalência pode ser explicada, ao menos em parte, pelo caráter do debate, que teve como objetivo principal trazer dados e informações para auxiliar a decisão do Supremo Tribunal Federal. Na leitura dos currículos dos/as expositores/as igualmente foi possível notar que grande parte possui formação acadêmica especializada, havendo um grande número de mestres/as e doutores/as nas mais diversas áreas do conhecimento.

O debate jurídico, incluído no eixo dos STCs, teve grande importância no cenário mais geral da audiência. De modo bastante significativo, essa discussão se amparou nos preceitos dos direitos humanos, direitos das mulheres e direitos sexuais e repordutivos, com ênfase para os 
acordos dos quais o Brasil é signatário. Como exemplo, é possível mencionar o Pacto de São José de Costa Rica, assinado pelo Brasil em 1969, que foi debatido tanto por grupos defensores da legalização do aborto quanto por opositores. Em diferentes momentos da audiência pública, pessoas trouxeram o trecho do pacto que atesta o direito à vida desde o momento da concepção.

Tal argumento consolida o entendimento jurídico do direito do nascituro como pressuposto dos direitos humanos. Contudo, essa é uma questão de intepretação, assim como argumentou a representante do Clínica de Direitos Humanos da Universidade Federal de Minas Gerais, Camila Silva Nicácio. Segundo ela, a Corte Internacional em diferentes situações considerou que esta afirmação não é uma premissa universal,_pois o texto do pacto usa a expressão “em geral” para tratar do direito à vida desde a concepção.

Outro dado importante em relação aos eixos argumentativos é que não pretendemos, aqui, estabelecer qualquer categorização hierárquica entre eles. Para este trabalho, todos foram considerados como igualmente válidos e pertinentes para a composição do debate. Por isso, optamos pelo uso da expressão “saberes”. Um bom exemplo é a fala da representante do Instituto Baresi, Adriana Abreu Magalhães Dias, que expôs suas experiências pessoais de uma mulher com deficiência. Ainda que muitos de seus argumentos não sejam amparados por um conhecimento técnico ou científico, ao tratar de suas vivências ela trouxe um importantíssimo viés para o debate, ressaltando que as mulheres com deficiência muitas vezes não são escutadas, mesmo quando se discute sobre elas.

Ademais, destacamos a prevalência do trânsito, ao longo das falas, por diferentes eixos e tendências. Assim, um/a expositor/a com formação jurídica, como é o caso, por exemplo, da Professora da USP Janaína Paschoal, não se resumiu a apresentar argumentos estritamente jurídicos. O mesmo vale para as instituições vinculadas a igrejas/religiões que, diversas vezes, pautaram seus discursos em dados, pesquisas e argumentos científicos. Esses elementos apontam para a complexidade do debate em torno da legalização do aborto, explicitada pela audiência pública no STF. O tema não é simples, mobiliza diferentes esferas da sociedade e tem caráter fortemente interdisciplinar. A relação com a laicidade, que escolhemos como enfoque, é apenas um dos muitos olhares que podem ser lançados sobre o assunto.

Como panorama geral sobre a apresentações, o quadro abaixo mostra quem foram os grupos que puderam expor seus argumentos na audiência pública, quem foram os/as 
representantes escolhidos/as, os eixos argumentativos que foram mobilizados e o enquadramento geral da fala (favorável ou contrário à descriminalização do aborto):

Tabela 2. Exposições na audiência pública sobre a ADPF442

\begin{tabular}{|c|c|c|}
\hline Instituição & Representante(s) & EA \\
\hline \multicolumn{3}{|l|}{ Primeiro dia - 03/08/2018 } \\
\hline MINISTÉRIO DA SAÚDE & $\begin{array}{l}\text { Mônica Almeida Neri } \\
\text { Maria de Fátima Marinho de Souza }\end{array}$ & STC \\
\hline FREBRASGO & Rosires Pereira de Andrade & $\begin{array}{l}\text { STC } \\
\text { SEF }\end{array}$ \\
\hline ACADEMIA NACIONAL DE MEDICINA & $\begin{array}{l}\text { José Gomes Temporão } \\
\text { Jorge Rezende Filho }\end{array}$ & STC \\
\hline INDICADA PELOS/AS CIDADÃOS/AS & Melania Amorim & STC \\
\hline INDICADO PELOS/AS CIDADÃOS/AS & Raphael Câmara & $\begin{array}{l}\text { STC } \\
\text { SPO }\end{array}$ \\
\hline $\begin{array}{l}\text { SOCIEDADE BRASILEIRA PARA O PROGRESSO DA } \\
\text { CIÊNCIA - SBPC }\end{array}$ & $\begin{array}{l}\text { Thomaz Rafael Gollop } \\
\text { Olímpio Moraes Filho }\end{array}$ & $\begin{array}{l}\text { STC } \\
\text { SEF }\end{array}$ \\
\hline $\begin{array}{l}\text { CENTRO DE PESQUISAS EM SAÚDE REPRODUTIVA } \\
\text { DE CAMPINAS - CEMICAMP }\end{array}$ & José Henrique Rodrigues Torres & $\begin{array}{l}\text { STC } \\
\text { SPO }\end{array}$ \\
\hline FUNDAÇÃO OSWALDO CRUZ - FIOCRUZ & $\begin{array}{l}\text { Marcos Augusto Bastos Dias } \\
\text { Mariza Theme-Filha }\end{array}$ & STC \\
\hline CONSELHO FEDERAL DE PSICOLOGIA & $\begin{array}{l}\text { Sandra Elena Sposito } \\
\text { Letícia Gonçalves }\end{array}$ & $\begin{array}{l}\text { STC } \\
\text { SEF }\end{array}$ \\
\hline INSTITUTO BARESI & Adriana Abreu Magalhães Dias & $\begin{array}{l}\text { SPO } \\
\text { STC }\end{array}$ \\
\hline $\begin{array}{l}\text { MOVIMENTO NACIONAL DA CIDADANIA PELA VIDA } \\
\text { - BRASIL SEM ABORTO }\end{array}$ & Lenise Aparecida Martins Garcia & STC \\
\hline ASSOCIAÇÃO NACIONAL PRÓ-VIDA E PRÓ-FAMÍLIA & Hermes Rodrigues Nery & $\begin{array}{l}\text { STC } \\
\text { SPO }\end{array}$ \\
\hline ANIS & Débora Diniz & $\begin{array}{l}\text { STC } \\
\text { SEF }\end{array}$ \\
\hline $\begin{array}{l}\text { CENTRO BRASILEIRO DE ANÁLISE E } \\
\text { PLANEJAMENTO }\end{array}$ & Tania Di Giacomo do Lago & $\begin{array}{l}\text { STC } \\
\text { SPO }\end{array}$ \\
\hline
\end{tabular}




\begin{tabular}{|c|c|c|}
\hline $\begin{array}{l}\text { INTERNATIONAL WOMEN'S HEALTH COALITION - } \\
\text { IWHC }\end{array}$ & Françoise Girard & STC \\
\hline CENTER FOR REPRODUCTIVE RIGHTS & Sebastián Rodríguez Alarcón & STC \\
\hline HUMAN RIGHTS WATCH & Verónica Undurraga & STC \\
\hline HEALTH, ACCESS, RIGHTS - IPAS & Anand Grover & STC \\
\hline INSTITUTO DE POLÍTICAS GOVERNAMENTAIS - IPG & Viviane Petinelli e Silva & STC \\
\hline $\begin{array}{l}\text { CONSÓRCIO LATINO-AMERICANO CONTRA O } \\
\text { ABORTO INSEGURO - CLACAI }\end{array}$ & Rebecca Cook & STC \\
\hline $\begin{array}{l}\text { ASSOCIAÇÃO BRASILEIRA DE ANTROPOLOGIA - } \\
\text { ABA }\end{array}$ & Lia Zanotta Machado & STC \\
\hline $\begin{array}{l}\text { REPRESENTAÇÃO COLETIVA DOS GRUPOS: } \\
\text { COLETIVO MARGARIDA ALVES DE ASSESSORIA } \\
\text { POPULAR, DEFEM, CRIOLA, CFSS, GRUPO CURUMIM } \\
\text { GESTAÇÃO E PARTO E CFEMEA }\end{array}$ & $\begin{array}{l}\text { Natália Mori } \\
\text { Fernanda Lopes } \\
\text { Ana Paula de A. Lima Vianna }\end{array}$ & $\begin{array}{l}\text { STC } \\
\text { SPO }\end{array}$ \\
\hline WOMEN ON WAVES & Rebecca Gomperts & $\begin{array}{l}\text { STC } \\
\text { SPO }\end{array}$ \\
\hline $\begin{array}{l}\text { CENTRO DE REESTRUTURAÇÃO PARA A VIDA- } \\
\text { CERVI }\end{array}$ & Rosemeire Santiago & SPO \\
\hline $\begin{array}{l}\text { ASSOCIAÇÃO DE DIREITO DA FAMÍLIA E DAS } \\
\text { SUCESSÕES - ADFAS }\end{array}$ & Regina Beatriz Tavares da Silva & $\begin{array}{l}\text { STC } \\
\text { SEF }\end{array}$ \\
\hline $\begin{array}{l}\text { SOCIEDADE BRASILEIRA DE BIOÉTICA - SBB E } \\
\text { INSTITUTO DE BIODIREITO E BIOÉTICA - IBIOS }\end{array}$ & $\begin{array}{l}\text { Dirceu Bartolomeu Greco } \\
\text { Sérgio T. de Almeida Rego } \\
\text { Heloisa Helena G. Barbosa }\end{array}$ & $\begin{array}{l}\text { STC } \\
\text { SEF } \\
\text { SPO }\end{array}$ \\
\hline \multicolumn{3}{|c|}{ SEGUNDO DIA - 06/08/2018 } \\
\hline CNBB & $\begin{array}{l}\text { Dom Ricardo Hoerpers } \\
\text { José Eduardo de O. e Silva }\end{array}$ & $\begin{array}{l}\text { STC } \\
\text { SPO } \\
\text { SEF }\end{array}$ \\
\hline CONAL & $\begin{array}{l}\text { Sílvia Maria de Vasconcelos } \\
\text { Palmeira Cruz }\end{array}$ & $\begin{array}{l}\text { STC } \\
\text { SPO }\end{array}$ \\
\hline CONVENÇÃO GERAL DAS ASSEMBLEIAS DE DEUS & $\begin{array}{lll}\text { Douglas } & \text { Roberto de Almeida } \\
\text { Baptista } & & \end{array}$ & $\begin{array}{l}\text { STC } \\
\text { SPO } \\
\text { SRT }\end{array}$ \\
\hline CONVENÇÃO BATISTA BRASILEIRA & Lourenço Stelio Rega & $\begin{array}{l}\text { SEF } \\
\text { STC }\end{array}$ \\
\hline INSTITUTO DE ESTUDOS DA RELIGIÃO & Lusmarina Campos Garcia & $\begin{array}{l}\text { SRT } \\
\text { STC } \\
\text { SPO }\end{array}$ \\
\hline
\end{tabular}




\begin{tabular}{|c|c|c|}
\hline UNIÃO ESPÍRITA BRASILEIRA & Luciano Alencar da Cunha & $\begin{array}{l}\text { SPO } \\
\text { STC }\end{array}$ \\
\hline UNIÃO DOS JURISTAS CATÓLICOS DE SÃO PAULO & Angela Vidal G. Martins Silva & STC \\
\hline CATÓLICAS PELO DIREITO DE DECIDIR & $\begin{array}{l}\text { Maria José Fontellas Rosado } \\
\text { Nunes }\end{array}$ & $\begin{array}{l}\text { SPO } \\
\text { STC }\end{array}$ \\
\hline $\begin{array}{l}\text { ASSOCIAÇÃO DOS JURISTAS EVANGÉLICOS - } \\
\text { ANAJURE }\end{array}$ & Edna Vasconcelos Zilli & STC \\
\hline CONFEDERAÇÃO ISRAELITA DO BRASIL & Michel Schlesinger & $\begin{array}{l}\text { SRT } \\
\text { SPO }\end{array}$ \\
\hline $\begin{array}{l}\text { FEDERAÇÃO DAS ASSOCIAÇÕES MUÇULMANAS DO } \\
\text { BRASIL }\end{array}$ & Mohsin Ben Moussa Al Ahassani & SRT \\
\hline CONSELHO NACIONAL DE DIREITOS HUMANOS & Fabiana Galera Severo & STC \\
\hline CONECTAS DIREITOS HUMANOS & Joana Madalena & STC \\
\hline $\begin{array}{l}\text { FRENTE PARLAMENTAR EM DEFESA DA VIDA E DA } \\
\text { FAMÍLIA }\end{array}$ & Magno Malta & $\begin{array}{l}\text { STC } \\
\text { SPO }\end{array}$ \\
\hline INSTITUTO BRASILEIRO DE DIREITO CIVIL & Ana Carla Harmatiuk Matos & STC \\
\hline SEM REPRESENTAÇÃO & Janaína Paschoal & STC \\
\hline INSTITUTO BRASILEIRO DE CIÊNCIAS CRIMINAIS & Eleonora Rangel Nacif: & STC \\
\hline DEFENSORIA PÚBLICA DA UNIÃO & Charlene da Silva Borges & $\begin{array}{l}\text { STC } \\
\text { SPO }\end{array}$ \\
\hline $\begin{array}{l}\text { DEFENSORIA PÚBLICA DO ESTADO DE SÃO PAULO - } \\
\text { NUDEM E CLÍNICA DE LITÍGIOS ESTRATÉGICOS DA } \\
\text { FGV DIREITO SP }\end{array}$ & Ana Rita Souza Prata & $\begin{array}{l}\text { STC } \\
\text { SPO }\end{array}$ \\
\hline $\begin{array}{l}\text { DEFENSORIA PÚBLICA DO ESTADO DO RIO DE } \\
\text { JANEIRO E CLINICA UERJ DE DIREITOS }\end{array}$ & Lívia Miranda Muller & STC \\
\hline ESTADO DE SERGIPE & José Paulo Leão Veloso Silva & $\begin{array}{l}\text { SPO } \\
\text { STC }\end{array}$ \\
\hline CLÍNICA DE DIREITOS HUMANOS DA UFMG & Camila Silva Nicácio & STC \\
\hline CLÍNICA UERJ DE DIREITOS & Cristina Telles & $\begin{array}{l}\text { STC } \\
\text { SPO }\end{array}$ \\
\hline $\begin{array}{l}\text { NÚCLEO DE PRÁTICA JURÍDICA EM DIREITOS } \\
\text { HUMANOS DA USP - NJP-DH-USP }\end{array}$ & Lívia Gil Guimarães & SPO \\
\hline
\end{tabular}

Fonte: ADPF442 
Como havíamos comentado anteriormente, o eixo dos saberes técnico-científicos foi de longe o mais mobilizado, sobretudo no que diz respeito às áreas de saúde e jurídica. Do total de 49 apresentações, 17 se posicionaram de forma contrária à ADPF 442 (linhas vermelhas) e, consequentemente, à descriminalização do aborto no Brasil; as demais (em verde) foram favoráveis. É preciso ressaltar, no entanto, que esses posicionamentos nem sempre foram claramente manifestados; em alguns casos eles foram deduzidos a partir da linha argumentativa presente no decorrer da exposição. Chama a atenção ainda, dentro desse panorama mais geral, a divisão entre homens e mulheres que expuseram seus argumentos. Dos/as 60 expositores/as, 22 eram homens e 38 mulheres; 10 homens se posicionaram contra a ADPF 442 e 12 a favor; dentre as mulheres, 8 foram contrárias e 30 favoráveis a ação.

Esses números apontam para a importância da posição das mulheres sobre a questão da IVG (lembrando que a própria relatora da ADPF442, a ministra Rosa Weber, é uma mulher). A maior parte das expositoras foi favorável à despenalização, enquanto entre os homens essa diferença se tornou bem menor. É impossível afirmar que as mulheres são mais favoráveis à descriminalização do aborto, mas seus posicionamentos revelaram, no mínimo, que o tema lhes era mais sensível e que o debate sobre a IVG está diretamente ligado às suas experiências, convicções pessoais, direitos, liberdade de decisão e papéis na sociedade.

No que diz respeito à relação entre a IVG e as compreensões religiosas acerca do tema, é possível notar que tal imbricamento se faz presente antes mesmo do debate, na composição das instituições e pessoas aceitas para expor suas reflexões nos dois dias de audiência. Grupos das principais religiões e igrejas do Brasil, além de organizações ligadas às religiões, integraram o debate em número significativo. Os argumentos de base religiosa, contudo, poucas vezes foram usados, havendo uma tendência geral para o debate técnico, racional e pautado por estudos científicos.

Do montante de apresentações, 11 foram consideradas em nossa análise como diretamente vinculados a alguma religião. Para tanto, adotamos como critério a origem da instituição representada e o currículo do/a representante. Dentre eles, apenas três se posicionaram favoravelmente à ADPF 442 e utilizaram argumentos que corroboram a descriminalização do aborto até a $12^{\mathrm{a}}$ semana de gestação. Na sequência, quando analisamos de forma aprofundada os argumentos mobilizados por esses grupos, notamos que o recorte pelo aspecto religioso das instituições expositoras é bem mais complexo do que se pode imaginar em um primeiro 
momento. O mais importante é observar que a relatora da ADPF 442, ministra Rosa Weber, considerou relevante ouvir as colocações de cada um desses grupos com o intuito de explicitar a decisão do STF sobre o tema. Dito de outro modo, para compor uma discussão democrática e plural sobre a descriminalização do aborto, foi fundamental ouvir os posicionamentos dos diferentes grupos religiosos.

Entrando mais especificamente no tema da laicidade ou do Estado laico, este foi bastante presente nas discussões sobre a ADPF 442, seja de forma direta ou indireta. Conforme as anotações em nosso diário de campo, as expressões "laico” e "laicidade” aparecem, ao longo da discussão, em 12 momentos diferentes, em discursos favoráveis à ADPF 442 e contrários. Além disso, em outros momentos a questão da laicidade aparece de forma indireta nos argumentos dos expositores, revelando uma oposição constante entre a fé e a razão na construção dos argumentos.

Uma das falas mais representativas sobre a questão da laicidade foi a da reverenda Lusmarina Campos Garcia, representante do Instituto de Estudos da Religião. Sua apresentação também foi uma das mais polêmicas, o que levou a uma série de manifestações posteriores, incluindo ameaças e ofensas pessoais em seus perfis. A exposição se organizou em torno de dois argumentos: o primeiro deles dizia respeito a não existência de orientações bíblicas para a condenação do aborto; o segundo focava justamente na laicidade do Estado e sua importância para a manutenção das liberdades individuais e religiosa. Assim, Lusmarina Campos Garcia iniciou sua fala mostrando como diferentes passagens bíblicas tratam o aborto, concluindo que as questões teológicas sobre o tema são históricas e diretamente relacionadas à misoginia latente ao cristianismo. No segundo argumento, a reverenda tratou da importância da separação entre “os dois reinos” feita por Lutero, enfatizando que a liberdade religiosa e a própria existência das igrejas protestantes se devem à liberdade religiosa garantida por um Estado laico. Segundo ela:

Um Estado laico não é um Estado ateu, mas é um Estado que não confunde os conceitos de crime e de pecado, nem se orienta por leis religiosas. As sanções do Estado não podem punir aqueles e aquelas que violem interesses ou dogmas das igrejas cristãs ou de outras religiões. É desse modo que o Estado laico protege a diversidade, não professando nenhuma verdade ou crença baseada nesta ou naquela tradição religiosa.

Além da pertinência na conceituação da laicidade, em conformidade com as definições de Bracho (2005) e Milot (2008), a fala da reverenda Lusmarina Campos Garcia coloca em perspectiva várias pré-concepções e binarismo ligados à discussão da legalização do aborto: não há, de um lado, cientistas favoráveis à legalização do aborto e, do outro, religiosos contrários; o 
eixo argumentativo que mobiliza saberes religiosos-teológicos não necessariamente se opõe à prática da interrupção voluntária da gestação; a desconstrução dos papéis de gênero pode ser feita por dentro das instituições religiosas; o Estado laico não se opõem à liberdade religiosa. Desse modo, quando falamos da laicidade na “corda bamba”, nos referimos ao equilíbrio delicado que o tema exige.

Para ilustrar outras formas de mobilização do argumento da laicidade, vale a pena recuperar o discurso proferido por Dom Ricardo Hoerpers, da CNBB. Logo no início de sua fala, afirma:

Querem nos desqualificar como fanáticos e fundamentalistas religiosos que impõem sobre o Estado laico uma visão religiosa. Onde está o fundamentalismo religioso em aderir aos dados da ciência que comprovam o início da vida desde a concepção? Onde está o fanatismo religioso em acreditar que todo atentado contra a vida é um crime?.

É curioso notar que a exposição rompe, a partir dessa sequência, uma relação préestabelecida entre fundamentalismo e conservadorismo no campo da moral. Além disso, a fala de Dom Ricardo Hoerpers estabelece uma vinculação com o Estado laico e se associa ao pensamento racional e científico. Não é por ser religioso que ele se opõe à legalização do aborto. Segundo o argumento construído, essa é uma acusação falsa, porque a defesa da vida se ampara em dados científicos. Nesse caso, se aplica com grande potencial a categoria criada por Juan Marco Vaggione (2006): o secularismo estratégico.

Este 'secularismo estratégico', constituye uno de los campos más importantes de análisis. Aunque estos discursos son 'racionales' no necesariamente presentan un nivel menor de dogmatismo que las creencias religiosas que los sostienen. De algún modo, el secularismo estratégico muestra la facilidad con que los sectores más conservadores amalgaman y fusionan discursos. Una facilidad que, irónicamente, deconstruye la dicotomía religioso/secular (VAGGIONE, 2006, pp. 61-62).

Com essa categoria analítica, o sociólogo argentino busca desfazer os pares sobrepostos: secular/religioso e progressista/conservador. Segundo ele, o discurso conservador mobiliza argumentos seculares em seu favor, ao mesmo tempo em que as dissidências religiosas revelam as possibilidades de progresso dentro do espaço religioso. Nesse sentido, não se pode dizer que a fala de Dom Ricardo não seja secular, mesmo sendo ele um defensor de crenças religiosas, do mesmo modo como a reverenda Lusmarina, com o auxílio de argumentos teológico-religiosos, faz oposição a esse conservadorismo. Vaggione (2006) afirma que é necessário superar a dicotomização entre o religioso e o secular. Para ele, o religioso e o secular se combinam de formas complexas, principalmente quando se observa as questões de gênero e sexualidade. De 
um lado, o secularismo estratégico borra os limites entre o discurso religioso e o secular, na medida em que combina o científico e o racional com aspectos embasados pela religião. Por outro, as dissidências dentro do espaço religioso o tornam mais aberto ao diálogo e à crítica.

O autor observa ainda que a tendência de separação entre o secular e o religioso, trazida pela secularização, dificulta o estabelecimento de alianças entre os setores progressistas da sociedade, ao mesmo tempo em que as igrejas têm um pacto duradouro com os setores mais conservadores. Conclui que é necessário repensar as relações entre o secular e o religioso a partir das dinâmicas sociais, que constroem novos espaços políticos, muitas vezes ofuscados pela noção de secularização.

\section{Considerações}

Ao acompanharmos a audiência pública no STF, foi possível perceber que essa expectativa de separação entre o secular e o religioso não se concretizou. Mesmo com um grande número de exposições advindas de instituições religiosas, não há uma predominância dos argumentos de base religiosa para a defesa de um posicionamento contrário à descriminalização do aborto. Dentro dos grupos categorizados como religiosos, posicionamentos favoráveis à descriminalização são construídos com base em argumentos teológico-religiosos, mostrando que as dissidências ocupam um papel estratégico na crítica interna ao conservadorismo religioso. A laicidade, assim, se complexifica, porque a simples separação entre Estado e Religiões não dá conta de resolver o problema das liberdades individuais e dos direitos de minorias, como ocorre

com a demanda pela legalização do aborto. É preciso adentrar essas múltiplas relações e compreendê-las de forma mais aprofundada para pensar alternativas que não recaiam na simples oposição entre religioso e secular.

\section{Referências}

BARDIN, Laurence. Análise de Conteúdo. Lisboa: Ed. 70, 2007.

BESSIN, Marc. Política da presença: as questões temporais e sexuais do cuidado. In: ABREU, Alice Rangel Paiva [et. al] (Orgs.). Gênero e trabalho no Brasil e na França: perspectivas interseccionais. São Paulo: Boitempo, 2016, p. 235-245. 
BLANCARTE, Roberto. El por qué de um Estado laico. Memoria de Ponencias I Foro Centroamericano de Libertades Laicas. Asociación Colectiva por el Derecho a Decidir, 1 ed. San José: Colectiva por el Derecho a Decidir, 2008, pp. 12-35.

BLANCARTE, Roberto J. ¿Cómo podemos medir la laicidad?. Estudios Sociológicos, vol. XXX, n. 88, 2012, pp. 233-247.

BRACHO, Carmén Villarino. Laicidad y Estado moderno: definiciones y procesos. Cuestiones Políticas No 34, jan-jun de 2005, p. 157-173.

BRASIL. Supremo Tribunal Federal. Audiência Pública Convocada para Discutir Aspectos Interpretativos dos arts. 124 e 126 do Decreto-lei no 2.848/1940 (Código Penal). Decisão com a Relação dos Inscritos Habilitados, Data, Ordem dos Trabalhos e Metodologia. Brasília, 04 de junho de 2018.

CLIFFORD, J. Notes on (Field)notes. In: SANJEK, Roger (ed) Fieldnotes: the makings of Anthropology. Ithaca and London: Cornell University Press, 1990. p. 47-70.

DELPHY, Christine. O inimigo principal. Revista Brasileira de Ciência Política, n. 17. Brasília, maio-agosto de 2015, p. 99-119.

FANTI, Fabiola. "Mobilização social e luta por direitos: movimento feminista e a campanha pela descriminalização e legalização do aborto no Brasil”. Trabalho apresentado no $10^{\circ}$ Encontro da Associação Brasileira de Ciência Política Belo Horizonte, 2016.

FOUCAULT, Michel. História da Sexualidade I: a vontade de saber. Rio de Janeiro: Graal, 2004.

GALEOTTI, Giulia. História do aborto. Lisboa: Edições 70, 2007.

HUNT, Lynn. A inveção dos direitos humanos: uma história. São Paulo: Companhia das Letras, 2009.

HURST, Jane. Uma história não contada. A história das ideias sobre o aborto na Igreja Católica. São Paulo: Católicas Pelo Direito de Decidir, 2000.

LAQUEUR, Thomas. Inventando o sexo: corpo e gênero dos gregos a Freud. Rio de Janeiro: Relume Dumará, 2001.

MILOT, Micheline. Laicidad y respeto a la diversidad cultural. In: RODRÍGUEZ, Elsa Conde; MARTÍNEZ, Martha T.; MAGALLÓN. Rosario O.; BLANCARTE; Roberto J. Estado laico, democracia y libertades. Cámara de Diputados/Congreso de la Unión, 2008, p. 45-52.

PATEMAN, Carole. O contrato sexual. Rio de Janeiro: Paz e Terra, 1993.

RUIBAL, Alba. Feminismo frente a fundamentalismos religiosos: mobilização e contramobilização em torno dos direitos reprodutivos na América Latina”. Revista Brasileira de Ciência Política, n. 14, Brasília, maio-agosto, 2014, p. 111-138. 
SANTOS, Naira Pinheiro dos. Gênero e situação de rua: representações sociais e práticas no contexto de instituições evangélicas de assistência social. In: SOUZA, Sandra Duarte de; SANTOS, Naira Pinheiro dos. Estudos feministas e religião. Tendências e debates. Volume 2. Curitiba: Prismas, 2015, p. 147-182.

SCAVONE, Lucila. A maternidade e o feminismo: diálogo com as ciências sociais. Cadernos Pagu (16) 2001: pp.137-150.

VAGGIONE, Juan Marco. Entre reactivos y disidentes: desandando las fronteras entre lo religioso y lo secular. (2006). Defensa de los derechos sexuales en contextos fundamentalistas. Buenos Aires: CDD-Córdoba, IGLHRC, 2006.

TAYLOR, Charles. Uma Era Secular. São Leopoldo: Unissinos, 2010.

Recebido em 29/03/2019.

Aceito em 04/05/2019.

\footnotetext{
${ }^{1}$ Aqui cumpre ressaltar que a audiência versou especificamente sobre a descriminalização, o que não implica necessariamente na legalização. O debate, contudo, excedeu essa especificidade da ADPF, havendo um entendimento bastante difundido de que ao acatar a ação do PSOL/ANIS o STF estaria promovendo a legalização da IVG no Brasil.
} 